\title{
The impact of radiant heat on various types of plasterboard walls
}

\author{
Stanislava Gašpercová1, ${ }^{*}$, Linda Makovická Osvaldová ${ }^{1}$, and Erik Richnavský ${ }^{1}$ \\ ${ }^{1}$ University of Žilina, Faculty of Security Engineering, Department of Fire Engineering, ul. 1. Mája \\ 32, 01026 Žilina, Slovak republic
}

\begin{abstract}
The future of the whole world focuses on reducing waste produced by people. As the construction sector is one of the biggest producers of waste, a great deal of effort has been made to introduce this trend in modern construction. The "green" building sector, therefore, draws attention to natural and recyclable building materials. These include natural thermal insulation such as cork, fiberboard, hemp insulation, and even sheep wool insulation. Almost all types of such insulation are made from waste materials which, were they not reused in the form of thermal insulation, would end up as municipal or biodegradable waste. At the same time, we should point out that almost all "green" construction materials are flammable. This feature is not very advantageous from the point of view of fire protection and it can significantly affect the fire safety of a construction. It is for this reason that the main objective of this research was to determine the impact of a radiant heat source on various types of thermal insulation used as plasterboard filling and to evaluate the possibilities of their use in sandwich constructions for fire protection purposes.
\end{abstract}

\section{Introduction}

Buildings are an integral part of human existence. We spend almost all our lives in the interior: the average person spends about $80 \%$ of his life inside buildings. It is therefore important to protect them against fire and such measures are stipulated in the basic requirements with which each building has to comply. Building structures are subjected to various forces during their service life, such as fire or explosion $[1,2,3]$.

The construction of buildings has undergone a long development in human history, from the oldest cave dwellings to modern skyscrapers hundreds of meters high. Major changes have occurred, not only in terms of the nature and geometry of the buildings, but also in terms of the type and characteristics of the materials used for the construction. Traditional "heavy" building materials were used in the past; nowadays there is a trend for brightening and lightening the structures $[4,5]$. As an example, we can mention the increasing use of plasterboard walls to partition the interior of buildings.

The 'green' building industry currently uses many natural or recycled building materials with high fire-heating values, not only for the furnishings but also within the building

\footnotetext{
*Corresponding author: stanislava.gaspercova@fbi.uniza.sk
} 
structures. It follows that the choice of building materials significantly influences the overall behavior of the building in the event of a fire, and it is therefore important to examine the materials and if possible, improve their properties. It is these facts that led us to establish a method and carry out an experimental examination of the impact of a radiant heat source on selected natural thermal insulation built in plasterboard walls $[6,7,8,9]$.

\section{Description of the samples and method of the experiment}

The first part of the experiment consisted of preparing the samples, $500 \times 500 \times 120 \mathrm{~mm}$ construction. The structure of the samples simulated the composition of a plasterboard dividing wall consisting of one layer of plasterboard on each side. There was thermal insulation filling between the plasterboards. The skeleton structure was made up of CW dry wall steel profiles, $100 \mathrm{~mm}$ wide, joined together with screws.

Standard plasterboards were used for the test. Mineral wool, wood fibre insulation and sheep wool were used as filling elements. Three sets of samples were created and differed from one another in the type of thermal insulation used. Five samples were tested in each set of samples, and an arithmetic mean was obtained from the results. These types of insulation were chosen because each of them represents a different kind of thermal insulation. Mineral wool is a standard type of building material which is manufactured from natural materials of mineral origin, but is basically impossible to recycle. Wood fiber is an environmentally friendly material of plant origin made from wood waste and can be ecologically disposed of after use. Sheep wool is a natural ecological material of animal origin which is also, in principle, waste material; its disposal is eco-friendly [10, 11, 12, 13]. In addition to their origins, these insulation materials also differ in their properties, such as the thermal conductivity coefficient or reaction to fire class (Table 1).

Table 1. Selected properties of thermal insulation materials.

\begin{tabular}{|l|c|c|c|}
\hline \multicolumn{1}{|c|}{ Selected properties } & Mineral wool & Wood fiber board & Sheep wool \\
\hline Reaction to fire class & A1 & E & E \\
\hline Density [kg/m $\left.\mathrm{m}^{3}\right]$ & 15 & 16 & 150 \\
\hline $\begin{array}{l}\text { Specific thermal } \\
\text { capacity [J/kg.K] }\end{array}$ & 840 & 2,000 & 1,720 \\
\hline $\begin{array}{l}\text { Thermal conductivity } \\
\text { coefficient [W/m.K] }\end{array}$ & 0.037 & 0.036 & 0.034 \\
\hline $\begin{array}{l}\text { Specific properties } \\
\text { under burning } \\
\text { conditions }\end{array}$ & $\begin{array}{c}\text { Melting } \\
\text { temperature } 1200 \\
-1600^{\circ} \mathrm{C}\end{array}$ & $\begin{array}{c}\text { Uncontrolled } \\
\text { smoldering and flame } \\
\text { propagation }\end{array}$ & $\begin{array}{c}\text { Flash point } \\
570-600^{\circ} \mathrm{C}\end{array}$ \\
\hline
\end{tabular}

The next part of the experiment was the construction of the measuring apparatus. For this purpose, a reverse T-shaped sample holder was created and a thermal radiator was mounted onto it as shown in Fig. 1. As our task was to determine the influence of thermal stress on building materials enclosed in a building structure, an infrared heater (described below) was chosen as the heat source. 
Fig. 1. Test apparatus.

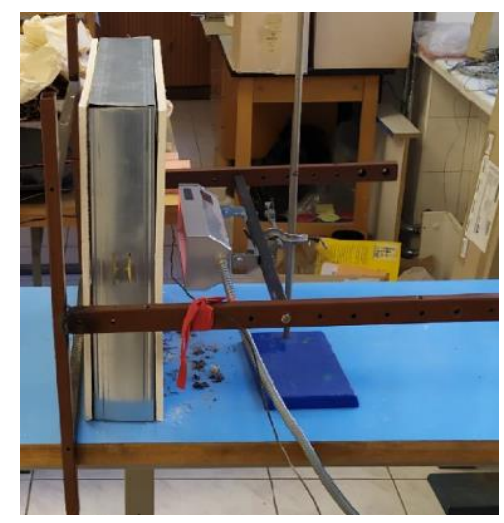

Holes were made on the supporting structure in order to mount the heater at different distances from the sample. The heater could also be mounted in different positions using screws. The infrared heater consisted of five heating tubes with a combined output of 1,500 W.

The temperature recording on the surface and inside the structure was carried out by means of two thermocouples connected to the AHLBORN ALMEMO 2690 measuring apparatus. The first thermocouple was located on the surface of the sample, and the second one inside the sample at a depth of $60 \mathrm{~mm}$ from the surface of the sample. Both thermocouples were placed in the center of the heated area of the sample.

The experimental method consisted of the following steps:

1. Specimens were mounted into the sample holder.

2. Thermocouples were positioned on the surface of the sample and inside the sample, $60 \mathrm{~mm}$ from the surface of the sample. Infrared heater was mounted onto the stand.

3. Infrared heater was switched on and heated to the steady-state heat flow for 20 minutes. After stabilization of the heat flow, the heater was placed $50 \mathrm{~mm}$ from the surface of the sample.

4. Sample was heated for 60 minutes.

5. Infrared heater was moved away from the sample.

6. Sample was removed from the sample holder and the upper layer was uncovered.

7. After removing the gypsum board, the reaction between oxygen and the thermal insulation was monitored.

\section{Results of Experimental Measurements}

When comparing the temperatures of the experimentally studied thermal insulation, we found that in the first three minutes the temperature in each thermal insulation was almost identical. After exposing the sample to a heat load for a longer period of time, a higher increase in temperature was observed between the 3rd and 15th minute of the experiment for sheep wool and mineral wool. From the 15th to approximately the 28th minute, the temperature increases for all types of thermal insulation were almost the same. Between the 28th and 60th minute, a significant increase in temperature was observed in the plasterboard samples insulated with sheep wool. This may have happened due to the fact that the thermal insulation burned away and an air pocket was formed (Fig. 2), which caused the thermocouple recording temperatures inside the thermal insulation to no longer 
be situated inside the thermal insulation, but in the air pocket. We discuss this in the following paragraph of this contribution.

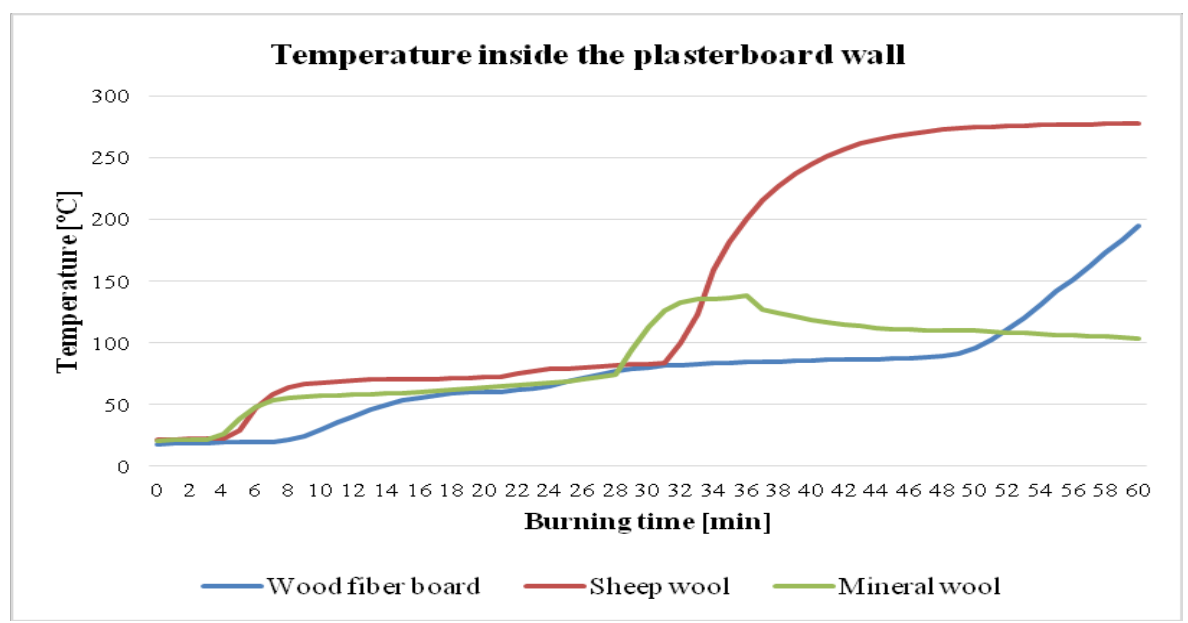

Fig. 2. Temperature diagram inside the plasterboard wall stressed by radiant heat.

In the experiment, the top layer of the gypsum board changed. The visual changes included: the top layer of plasterboard (paper) burned away and the gypsum started to release bound water, the evaporation of which caused cracks. However, these did not affect the heat transfer inside the structure. After finishing the experiment and uncovering the plasterboard layer on the heated side of the sample, damage to the thermal insulation was detected, which is documented in Fig. 3.

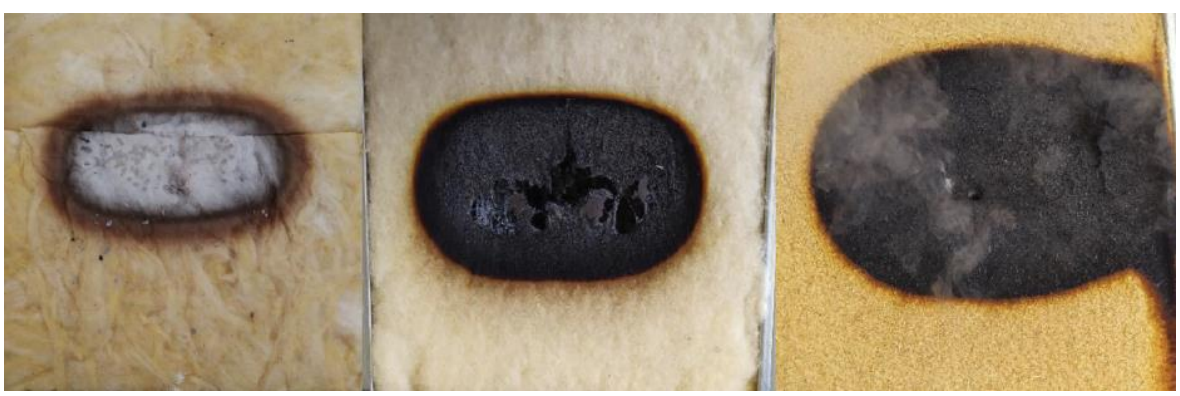

Fig. 3. Different types of thermal insulation after exposure to a radiant heat source.

As part of the visual monitoring of the impact of radiant heat on different types of thermal insulation, the following conclusions were made. Mineral wool sample was the least degraded, on the other hand, the wood fiberboard sample was the most degraded (Table 2).

Table 2. Dimensions of thermal damage of insulation samples

\begin{tabular}{|l|c|c|c|}
\hline \multicolumn{1}{|c|}{ Size [mm] } & Mineral wool & Wood fiber board & Sheep wool \\
\hline Height & 80 & 250 & 200 \\
\hline Length & 150 & 300 & 250 \\
\hline Width & 15 & 60 & 40 \\
\hline
\end{tabular}


In the case of mineral wool, the insulation did not smoulder or burn away. The material was thermally degraded only on the surface. As for the sheep wool sample, the isolation grouting and foul-smelling smoke occurred during the experiment. An air pocket was formed behind the sheathing, which prevented further carbonisation of the insulation. At the end of the experiment, grouting and carbonization did not continue. In the wood fiber insulation experiment, the insulation burned flamelessly and this continued even after the heat source was put away. The burning stopped only after the insulation was immersed in the water. This is particularly significant when considering the possibility of hidden fires, because a fire can spread uncontrollably inside the construction and therefore anywhere throughout a building. Significant smoke was also observed from the wood fiber insulation; in the case of a fire, this could make it difficult for one to navigate out of a building insulated with wood fiber, which would create significant smoke.

\section{Conclusion}

When comparing the thermal properties of synthetic and natural insulating materials, we can see that their properties are at a comparable level and therefore, the choice of insulation material is insignificant from a construction point of view $[14,15]$. However, this is not true in the context of the fire safety of buildings, as the fire performance of natural and synthetic thermal insulation materials varies significantly.

After testing various types of insulation, we conclude that it is possible to use sheep wool as an eco-friendly thermal insulation if it is not a fire separating structure. We do not recommend wood fiber insulation due to the possible uncontrolled hidden spread of a fire. However, if the contractors require wood fiber insulation, in constructions without a fire separation function, it is recommended that separation (insulation) strips be used between the individual wood fiber boards in both the longitudinal and transverse directions so that in the event of a fire, smoldering does not spread among the boards.

This work was supported by project $033 Z ̌ U-4 / 2019$, "The integration of practical training in the rescue services study."

\section{References}

1. L. Figuli, et al, IOP Conf. Ser. Earth Environ. Sci. 44 (2016).

2. L. Figuli, Z. Zvaková, C. Bedon, Procedia Eng. 192 (2017)

3. R. Erdelyiova, L. Figuli, M. Ivanco. MATEC Web of Conferences 313, 00033 (2020)

4. L. Figuli, Papan, D. APPLIED MECHANICS AND MATERIALS 617, (2014).

5. Z. Zvaková. Production management and engineering sciences. 577-581, (2016).

6. A. Iringová, D. Vandličková, M. Diviš. Central Europe towards Sustainable Building. (2019).

7. A. Iringová, D. Vandličková, M. Diviš. XXVIII. R-P-S Seminar. Theoretical Foundation of Civil Engineering. 1-8, (2019).

8. A. Iringová. XXVII R-S-P Seminar. Theoretical Foundation of Civil Engineering. (2018).

9. I. Murin et al. Procedia economics and finance. 34, (2015).

10. J. Zelený et al. ICERI 2013. 3985-3989, (2013).

11. I. Marková, I. Klement. Wood research. 48, 53-61, (2003).

12. P. Mitrenga, M. Vandlíčková, M. Dušková. Production management and engineering sciences. 481-485, (2016). 
13. M. Polorecká, J. Svetlík, J. Mitrengová. INTED 2020. 5048-5053, (2020).

14. I. Coneva, M. Vandlíčková, J. Svetlík. Advances in fire and safety engineering 2019. $1-5,(2019)$.

15. M. Vandlíčková. Burning and explosion. (in Slovak). EDIS, University of Žilina, p. 79, (2018). 